\title{
HIDROGEOLOGIA DA FORMAÇÃO SERRA GERAL NO ESTADO DE MATO GROSSO DO SUL
}

\section{HYDROGEOLOGY OF THE SERRA GERAL FORMATION, PARANÁ SEDIMENTARY BASIN, IN MATO GROSSO DO SUL STATE, BRAZIL}

\author{
Giancarlo Lastoria ${ }^{1}$; Osmar Sinelli ${ }^{2}$ Chang Hung Kiang ${ }^{3}$; Ian Hutcheon ${ }^{4}$; \\ Antônio Carlos Paranhos Filho ${ }^{1}$ e Didier Gastmans ${ }^{3}$
}

Recebido em:14/12/2005; aceito em: 17/07/2006

\begin{abstract}
RESUMO O Sistema Aqüífero Serra Geral aflora em uma área de $40.000 \mathrm{Km}^{2}$, na região centro sul do Estado de Mato Grosso do Sul. Em sua área de ocorrência concentra-se $61 \%$ da população do Estado, que tem se utilizado da sua água subterrânea para o abastecimento à população e à crescente atividade agro-industrial. Caracteriza-se por ser um aqüífero livre, anisotrópico e com porosidade de fissuras. A importância regional deste aqüífero levou a elaboração do presente estudo, que, a partir de uma abordagem de enfoques geológico-estrutural, hidrodinâmico e hidroquímico, permitiram a elaboração de um modelo hidrogeológico conceitual para o Sistema Aqǘf́ero Serra Geral na área de estudo. Este modelo aponta para uma predominância do fluxo e acúmulo das águas subterrâneas em sistemas de juntas horizontais de grande continuidade, contrariamente ao modelo de fluxo de água nas zonas de lineamentos verticais nos basaltos, tradicionalmente utilizado.
\end{abstract}

Palavras-chave: sistema aqüífero Serra Geral, aqüífero fissural, Mato Grosso do Sul, modelo hidrogeológico conceitual.

\begin{abstract}
The Serra Geral Formation is exposed over an area of $40,000 \mathrm{~km}^{2}$, in the south-central region of the Mato Grosso do Sul State, and constitutes an important aquifer in this region. More than $61 \%$ of the population of the state is concentrated in this area, and this groundwater is used for public supply, as well as acting as a source of water for the expanding industrial and agricultural ativities. The aquifer is caracterized as unconfined, heterogeneous and with porous fissures. The regional importance of this aquifer prompted the present hydrogeological study, with emphasis on geologicalstructural, hydrodynamic and hydrochemical aspects, permitting a construction of a conceptual hydrological model for the Serra Geral Aquifer System for this area. This model indicates horizontal joints of great continuity as being the principal zones of circulation and accumulation of water, in contrast to the traditionally used model of vertical groundwater flow in the basalt.
\end{abstract}

Key words: Serra Geral aquifer system, fractured aquifer, Mato Grosso do Sul State, conceptual hydrogeological model.

\section{INTRODUÇÃO}

A Formação Serra Geral é composta por uma seqüência de derrames basálticos e arenitos intertrapeanos, de idade jurássica-cretácica (CORDANI; VANDOROS, 1967). A grande expressão geográfica da área ocupada pelos basaltos desta formação dentro da Bacia Sedimentar do Paraná (Figura 1), despertou o interesse de muitos pesquisadores, que estudaram diversos aspectos relativos a estas rochas.

Embora a Formação Serra Geral constitua um dos aquíferos mais conhecidos e explotados da Bacia Sedimentar do Paraná, até hoje persistem dúvidas quanto à sua prospecção com vistas à definição dos reservatórios e seus modos de ocorrência dentro dos derrames basálticos (LASTORIA, 2002). No Estado de Mato Grosso do Sul, os basaltos da Formação Serra Geral representam um dos principais aqüíferos, se não o mais importante, pois em sua área de afloramento estão localizadas as duas microrregiões mais densamente habitadas do Estado, Campo Grande e Dourados, que concentram cerca de $60 \%$ da população estadual, segundo dados da Secretaria Estadual de Finanças, Orçamento e Planejamento-EFOP-MS (1998).

A potencialidade agrícola dos solos provenientes da decomposição dos basaltos e a localização da capital e da segunda maior cidade do Estado, nestas duas microrregiões, propiciaram esta concentração populacional, que tem buscado no Sistema Aqüífero Serra Geral sua fonte de suprimento de água, seja para o abastecimento público, seja para a atividade agroindustrial, devido fundamentalmente à facilidade e ao custo de construção dos poços tubulares para a sua captação, aliado à qualidade da água e às vazões obtidas.

\footnotetext{
${ }^{1}$ Universidade Federal de Mato Grosso do Sul - Departamento de Hidráulica e Transporte (lastoria@nin.ufms.br), (paranhos@nin.ufms.br)

${ }^{2}$ Engenharia Ambiental-Faculdades COC/Ribeirão Preto (osmarsinelli@coc.com.br )

${ }^{3}$ LEBAC-Laboratório de Estudos de Bacias - IGCE - UNESP (chang@rc.unesp.br), (gastmans@rc.unesp.br)

${ }^{4}$ Department of Geology and Geophysics - University of Calgary - Canadá (ian@earth.geo.ucalgary.ca)
} 


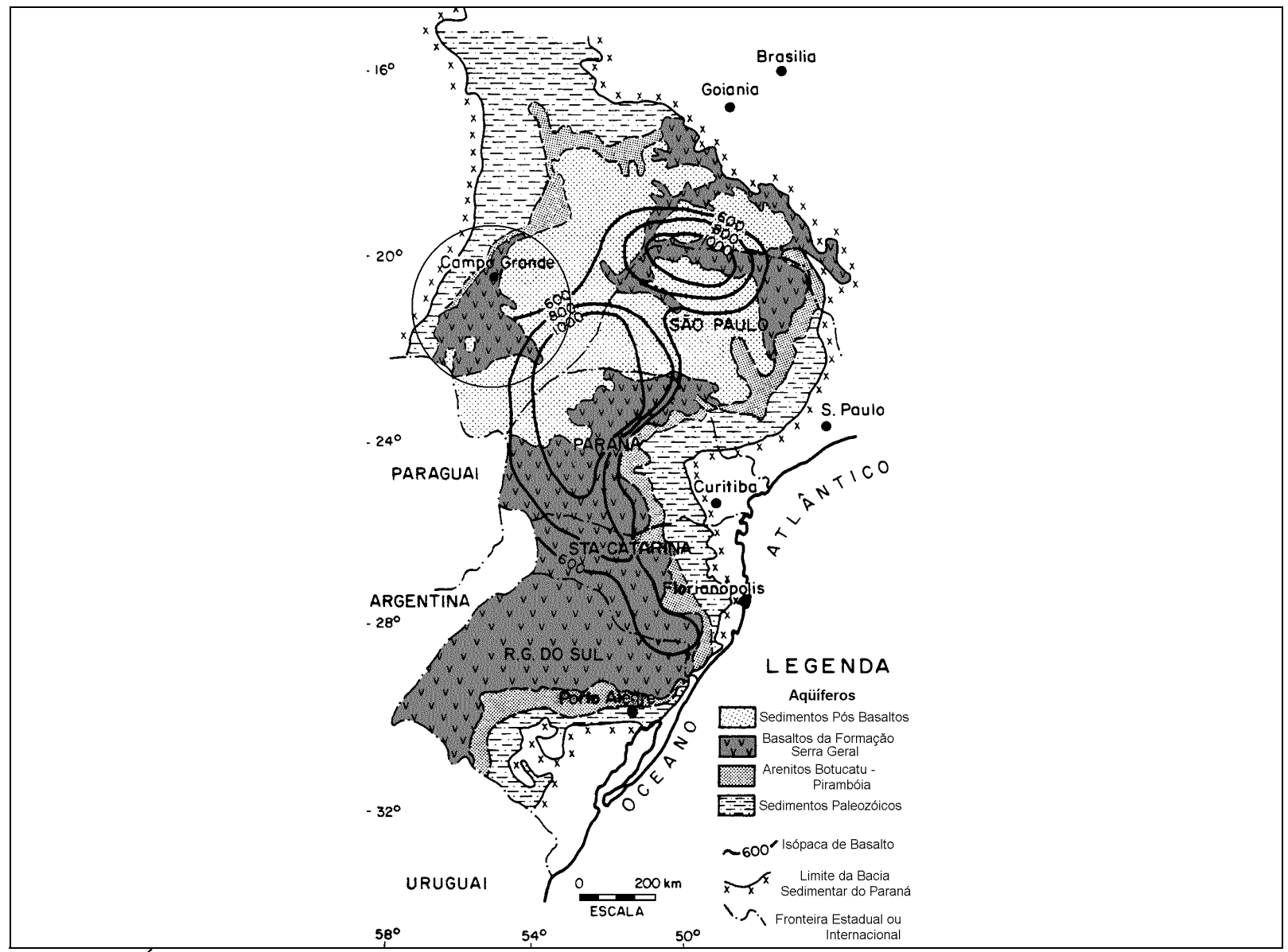

Figura 1- Área de ocorrência dos derrames basálticos (Sistema Aquífero Serra Geral) em território brasileiro (Modificado de Rebouças, 1978

Figure 1- Outcrop of basalt lava flows (Serra Geral Aquifer System) in Brazilian territory (Modified from Rebouças, 1978)

No Estado de Mato Grosso do Sul, os basaltos da Formação Serra Geral representam um dos principais aqǘferos, se não o mais importante, pois em sua área de afloramento estão localizadas as duas microrregiões mais densamente habitadas do Estado, Campo Grande e Dourados, que concentram cerca de $60 \%$ da população estadual, segundo dados da Secretaria Estadual de Finanças, Orçamento e Planejamento-EFOP-MS (1998).

A potencialidade agrícola dos solos provenientes da decomposição dos basaltos e a localização da capital e da segunda maior cidade do Estado, nestas duas microrregiões, propiciaram esta concentração populacional, que tem buscado no Sistema Aquíifero Serra Geral sua fonte de suprimento de água, seja para o abastecimento público, seja para a atividade agroindustrial, devido fundamentalmente à facilidade e ao custo de construção dos poços tubulares para a sua captação, aliado à qualidade da água e às vazões obtidas.

O objetivo do presente estudo é apresentar um modelo hidrogeológico conceitual regional para o Sistema Aqüífero Serra Geral, na área de afloramento dos basaltos da formação homônima para o Estado de Mato Grosso do Sul, baseado em informações hidrodinâmicas de poços, bem com no arcabouço geológico estrutural da área, responsável pelas grandes feições estruturais existentes, e dados hidroquímicos de amostras de água subterrânea.

\section{Localização da Área de Estudo}

A área de estudo encontra-se na região centro sul do Estado de Mato Grosso do Sul, tendo como referência as cidades de Campo Grande, próximo ao limite norte, e Dourados, na sua parte sudeste. Geograficamente localiza-se entre os paralelos $19^{\circ} 30^{\prime} \mathrm{S}$, ao norte de Campo Grande, e $23^{\circ} 20^{\prime} \mathrm{S}$, ao sul, na divisa com a República do Paraguai. A oeste a área é limitada pela Serra de Maracajú, na coordenada geográfica $56^{\circ} \mathrm{WG}$. O limite oriental da área fica definido no contato com os sedimentos pós-basálticos, atingindo no máximo a longitude $54^{\circ} \mathrm{WG}$ (Figura 2).

Ocupa uma área aproximada de $40.000 \mathrm{~km}^{2}$, representando a zona de afloramento dos derrames basálticos da Formação Serra Geral no Estado de Mato Grosso do Sul. 


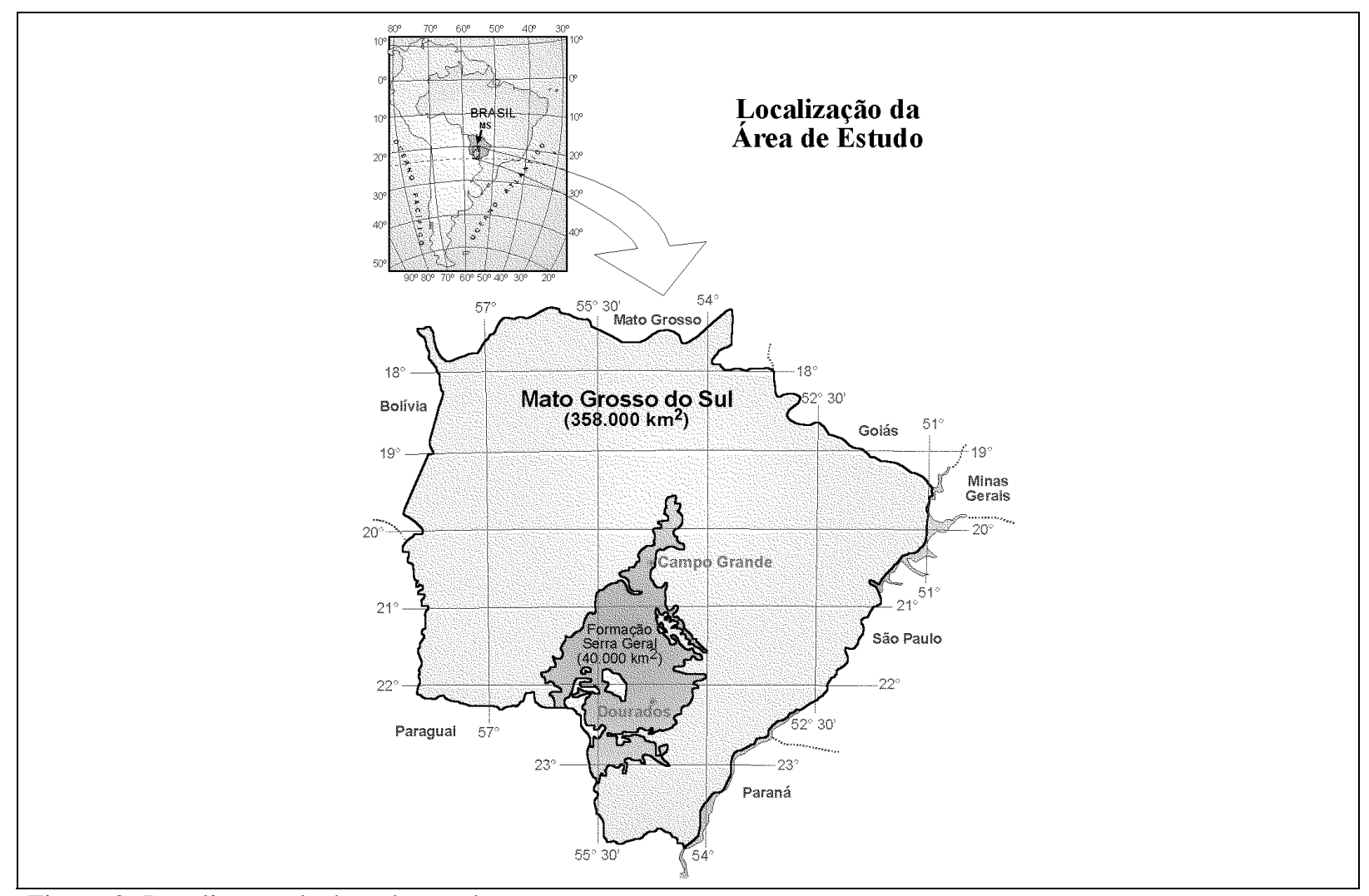

Figura 2- Localização da área de estudo

Figure 2- Location of study area

\section{Contexto Geológico Estrutural}

A área de estudo encontra-se inserida na Bacia Intra-cratônica do Paraná, estabelecida sobre a plataforma Sul-Americana a partir do Ordoviciano/Siluriano (ALMEIDA, 1967), que tem nessa região a sua borda oeste, grosso modo orientada para norte-nordeste, a partir da região de Bela Vista, ao sul, até a área de Pedro Gomes - rio Correntes, ao norte. Os mergulhos regionais das camadas são para leste, de origem tectônica, relacionados ao levantamento escalonado das serras da Bodoquena, de Maracajú e de São Jerônimo, sendo a última ao longo da sutura crustal de Coxim (HASSUI et al., 1993).

Este arcabouço geológico é controlado por um grande número de alinhamentos, altos e megassuturas existentes na Bacia Sedimentar do Paraná, descritas por Northfleet et al. (1969), Zalán et al. (1990), entre outros.

Estes elementos estruturais que limitam o quadro geológico da Bacia Sedimentar do Paraná, compartimentam o Estado de Mato Grosso do Sul em blocos, formando um mosaico estrutural, em que cada bloco possui características próprias, tanto em superfície, como em sub-superfície. Esta diversidade é herdada de uma movimentação estrutural específica para esta borda da bacia, através do tempo geológico, em especial no Fanerozóico, com elevação de alguns blocos em relação a outros e consequiente remoção, por erosão de várias unidades estratigráficas (FULFARO; PERINOTTO, 1994).

$\mathrm{Na}$ área dominada pela sequiência vulcanosedimentar da Bacia do Paraná, no Mato Grosso do Sul, os alinhamentos transversais noroeste mais importantes no estabelecimento do arcabouço estrutural dessa região são: do norte para o sul, Guapiara, São Jerônimo - Curiúva, Rio Alonzo e a Estrutura do rio Piquiri, além do alinhamento do Paranapanema, de direção EW, e o arco de Campo Grande, localizado entre os alinhamentos de Guapiara e São Jerônimo (Figura 3).

No estado de Mato Grosso do Sul a Formação Serra Geral (Kjsg) ocupa uma área de $178.000 \mathrm{~km}^{2}$, na sua porção centro-leste, sendo $40.000 \mathrm{~km}^{2}$ aflorante e o restante subjacente aos sedimentos do Grupo Bauru (TAHAL/SANESUL, 1998). Está assentada sobre os arenitos eólicos da Formação Botucatu $(\mathrm{Kjb})$, e capeada pelos arenitos continentais flúvio-lacustres do Grupo Bauru $(\mathrm{Kb})$, com contato superior discordante e erosivo, e contato inferior concordante e interdigitado, devido à contemporaneidade das duas formações (LASTORIA, 2002). 


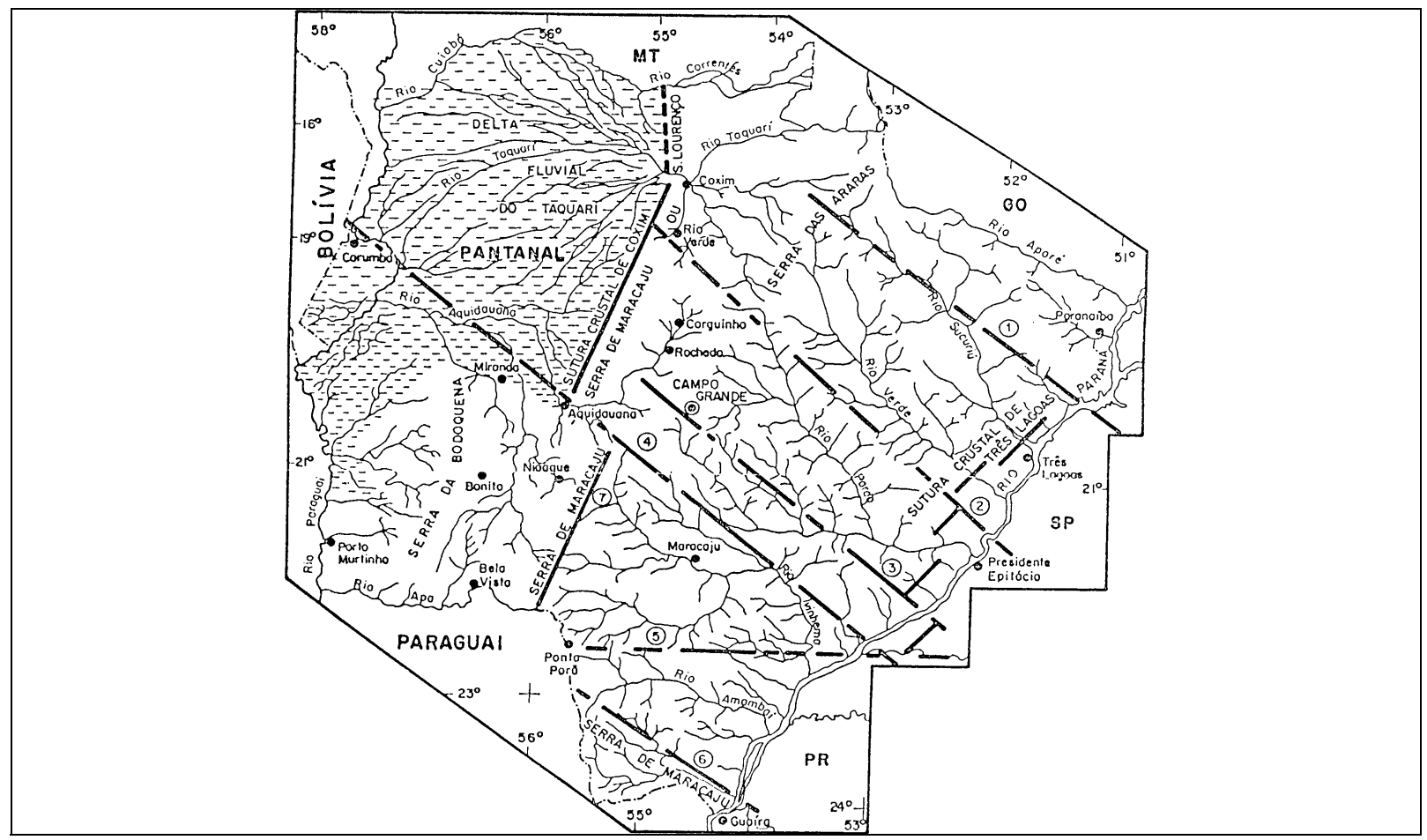

Figura 3- Arcabouço estrutural do Estado de Mato Grosso do Sul. 1- Alinhamento do Rio Tietê; 2- Alinhamento de Guapiara - Presidente Prudente; 3- Alinhamento São Jerônimo - Curiúva; 4- Alinhamento do Rio Alonzo; 5-Alinhamento do Paranapanema; 6- Alinhamento do Rio Piqueri; 7- Provável Sutura Crustal (FULFARO; PERINOTTO, 1994)

Figure 3- Structural framework of Mato Grosso do Sul State. 1- Rio Tiête Lineament; 2- Guapiara - Presidente Prudente Lineament; 3- São Jerônimo - Curiúva Lineament; 4- Rio Alonzo Lineament; 5- Paranapanema Lineament; 6 - Rio Piqueri Lineament; 7- Probable Crustal Suture (FULFARO; PERINOTTO, 1994)

Os basaltos da Formação Serra Geral apresentam espessuras, atestadas pela perfuração de poços tubulares e poços estratigráficos da Petrobrás, que variam de $200 \mathrm{~m}$ no município de Maracajú, $400 \mathrm{~m}$ em Dourados, de 100 a $350 \mathrm{~m}$ em Campo Grande, 400 a $500 \mathrm{~m}$ na cidade de Ponta Porã, e menos de 50 m em Amambaí.

Na região de Dourados, na margem direita do Rio Serrote, nota-se um sistema estrutural constituído por, pelo menos, dois sistemas de falhamentos com direções noroeste e nordeste, que acompanham os rios Dourados e Brilhante. A movimentação mostra um levantamento na parte sul e rebaixamento na parte norte e, em direção à leste. Dentro deste sistema, a partir do alto existente na cidade de Itaporã, em direção noroeste, as espessuras voltam a diminuir até as cidades de Vista Alegre e Maracajú, onde os basaltos têm espessuras de 150 a 200 m (Figura 4).

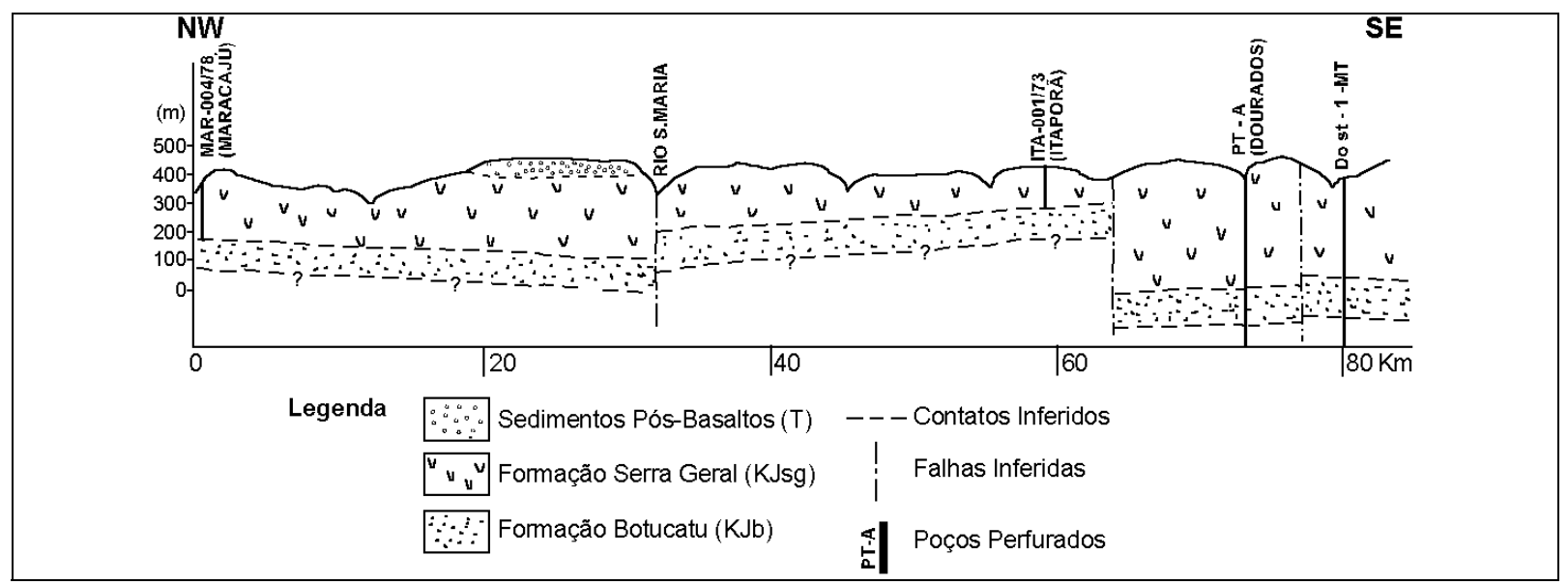

Figura 4- Perfil Geológico de Dourados a Maracajú, mostrando a diminuição da espessura do basalto em direção NW, a partir do alto de Itaporã

Figure 4- Geological Section from Dourados to Maracajú, showing thickness decrease in basalt to NW direction, starting from Itaporã elevation 
As principais direções estruturais da Bacia do Paraná (NW-SE e NE-SW) controlam o arcabouço estrutural também na cidade de Campo Grande, subdividindo a localidade em diversos blocos, provocando variação nas espessuras de basalto entre 100 e $350 \mathrm{~m}$.

A composição mineralógica dos basaltos foi estimada em amostras coletadas na Pedreira SULTEPA em Dourados, representando níveis maciços e vesiculares dos derrames.

O basalto maciço apresenta-se constituído por plagioclásio (labradorita), augita como piroxênio principal, na proporção de $40 \%$ e $30 \%$, respectivamente, e como minerais acessórios magnetita (transformada parcialmente em gohetita), olivina, apatita, clorofilita (com lamelas de clorita) e vidro devitrificado.

Os níveis com estrutura vesiculoamigdaloidal, a composição mineralógica é semelhante à observada nas amostras de estrutura maciça, e as vesículas apresentam-se geralmente preenchidas por esmectitas.

\section{Morfogênese dos Derrames da Formação Serra Geral}

A dinâmica de circulação de água nos basaltos está diretamente relacionada com os sistemas de descontinuidades nos derrames basálticos, tanto nas estruturas tectônicas, como nas interfaces de derrames e nas estruturas de origem atectônica (LASTORIA, 2002).

Diversos autores discorreram a respeito do fluxo de águas subterrâneas nos derrames basálticos da Bacia Sedimentar do Paraná, Hausmann (1974) afirma que o fluxo das águas neste tipo de rocha é orientado pelo padrão de disjunção do basalto e, em geral, são as juntas verticais que permitem uma circulação mais franca pela ação da gravidade.

Rebouças; Fraga (1988) apresentam um modelo genérico do comportamento hidrogeológico dos basaltos da Formação Serra Geral (Figura 5), subdividindo o aqüífero em duas unidades, uma superior, representada pelo produto da alteração intempérica dos basaltos, limitado na base por uma superfície de descontinuidade física, que representaria uma zona de alta permeabilidade.

A unidade inferior, situada abaixo desta descontinuidade, apresentaria como zona preferencial para a circulação de água a região do topo dos derrames, caracterizada pela ocorrência de estruturas vesiculares, e intenso fraturamento horizontal, com a circulação vertical ocorrendo nas diáclases existentes na porção central do derrame.

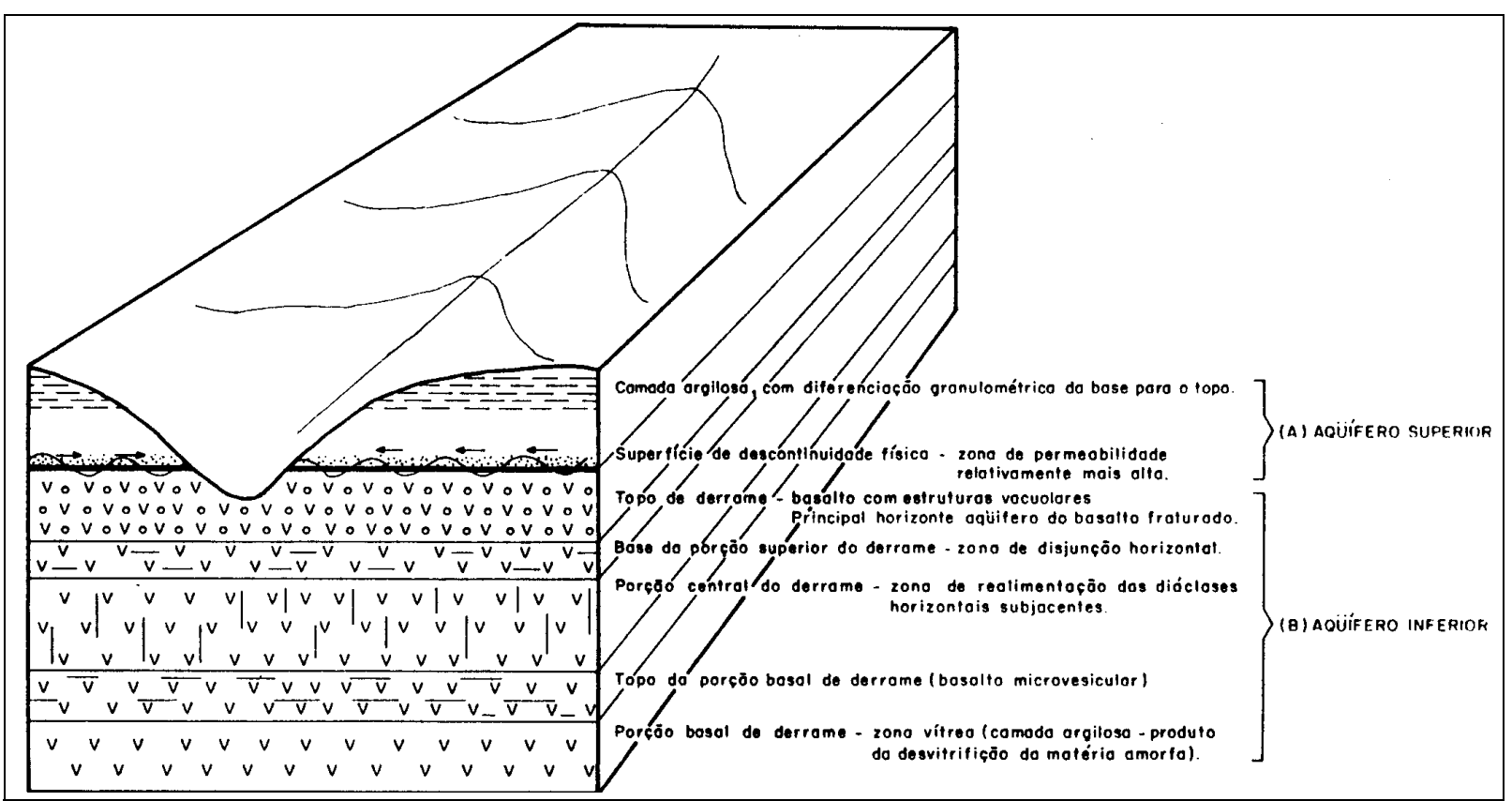

Figura 5- Modelo simplificado de ocorrência de água subterrânea no Sistema Aqüífero Serra Geral (REBOUÇAS;FRAGA, 1988)

Figure 5- Simplified model of groundwater occurrence in Serra Geral Aquifer Sistem (REBOUÇAS; FRAGA, 1988) 
Segundo Bagolini

(1971)

as descontinuidades horizontais seriam originadas devido ao fluxo diferencial na base dos derrames, em função da solidificação diferencial do magma, com conseqüente geração de superfícies de atrito nesta região do derrame.
Já na zona intermediária do derrame, o sistema de descontinuidades é preferencialmente vertical, representado por diáclases, com aspecto pseudo-colunar, enquanto que na porção superior do derrame são encontradas estruturas associadas ao escape de gases, com aspecto vesicular escoriáceo, e diaclasamento horizontal (Figura 6).

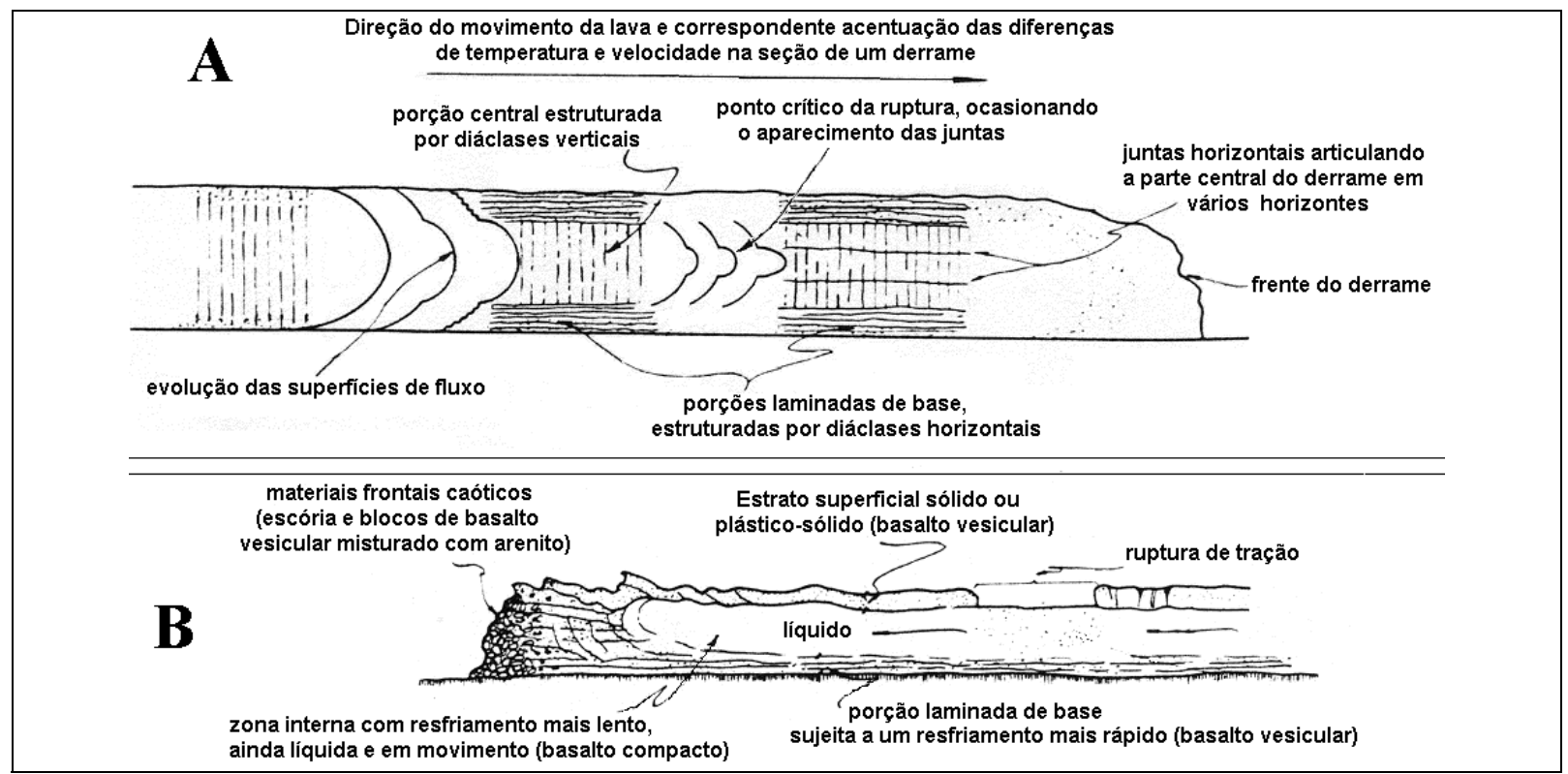

Figura 6- Morfogênese dos derrames basálticos no Brasil meridional (BAGOLINI, 1971)

Figure 6- Morphogenesis of the basaltic lava flows in meridional Brazil (Bagolin, 1971)

Aspectos Hidrogeológicos do Sistema Aqüífero Serra Geral em Mato Grosso do Sul

A caracterização de parâmetros hidrogeológicos do Sistema Aquiífero Serra Geral no Estado de Mato Grosso do Sul foi realizada a partir do cadastro de poços tubulares pertencentes a SANESUL (170 poços), aos quais foram adicionados dados de 287 poços tubulares de proprietários particulares perfurados na cidade de Campo Grande, totalizando um universo amostral de 457 poços tubulares.

As profundidades dos poços tubulares perfurados nos basaltos da Formação Serra Geral analisados, mostram valores variando entre 30 e $300 \mathrm{~m}$, observando-se que a grande maioria dos poços apresenta profundidade entre 100 e $150 \mathrm{~m}$ (Figura 7).

A análise dos dados cadastrais dos poços perfurados no basalto, no âmbito da área de estudo, aliada às observações obtidas durante o acompanhamento de inúmeras perfurações realizadas na área de afloramento da Formação Serra Geral, indica que, geralmente, o aumento de profundidade dos poços não corresponde a um aumento linear da vazão, não existindo, portanto relação entre profundidade dos poços e vazão (Figura 8).

Este fato tem implicação prática importante no projeto construtivo de um poço tubular que venha a ser perfurado no Sistema Aquíffero Serra Geral. A profundidade final do poço deve ser controlada pela presença de estruturas horizontais nesta rocha (juntas, contatos, diáclases).

Para os poços perfurados na cidade de Campo Grande, que captam água no Sistema Aqüífero Serra Geral, a estatística básica dos principais parâmetros hidrodinâmicos é apresentada na tabela 1 .

Observa-se que, como conseqüência da heterogeneidade dos sistemas de descontinuidades nos basaltos, os parâmetros hidráulicos analisados apresentam desvios padrão muito altos, sendo, desta maneira, os valores das medianas mais representativos que os valores das médias. 


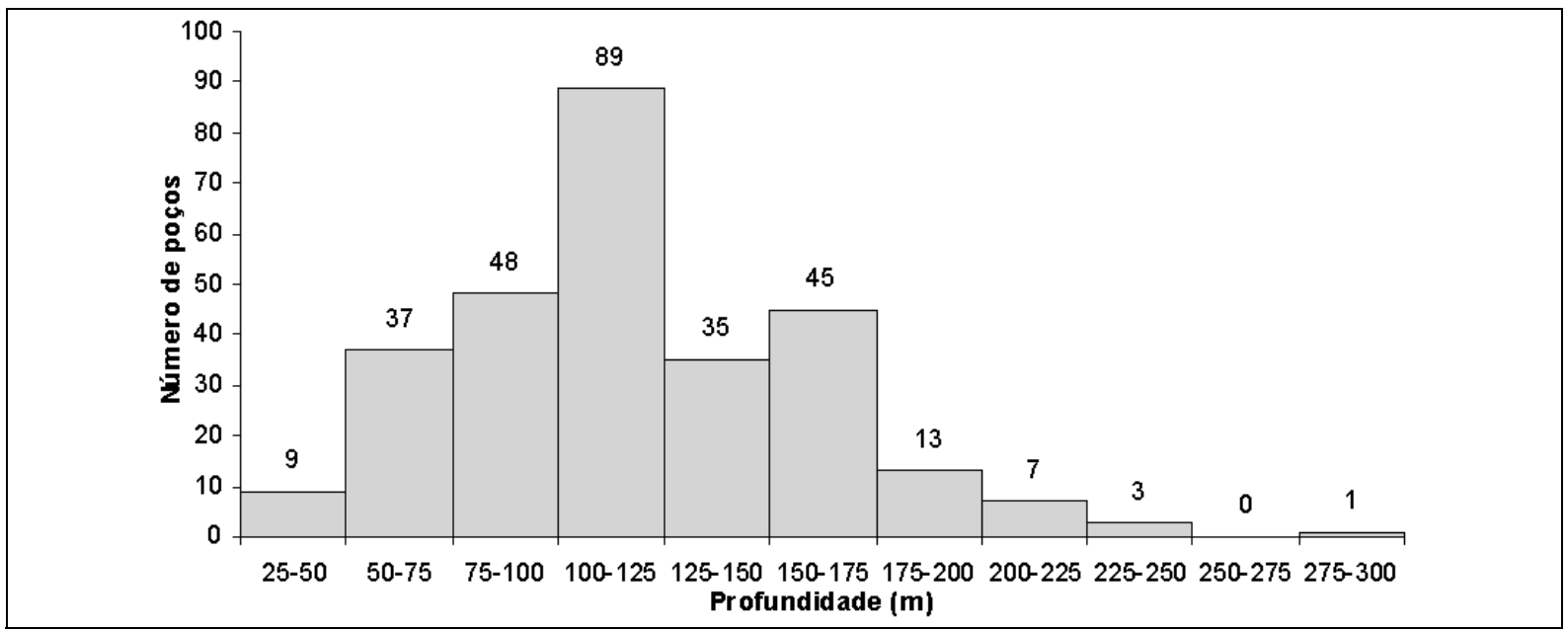

Figura 7- Distribuição das Profundidades dos poços tubulares perfurados em Campo Grande Figure 7- Depth distribution of wells in Campo Grande

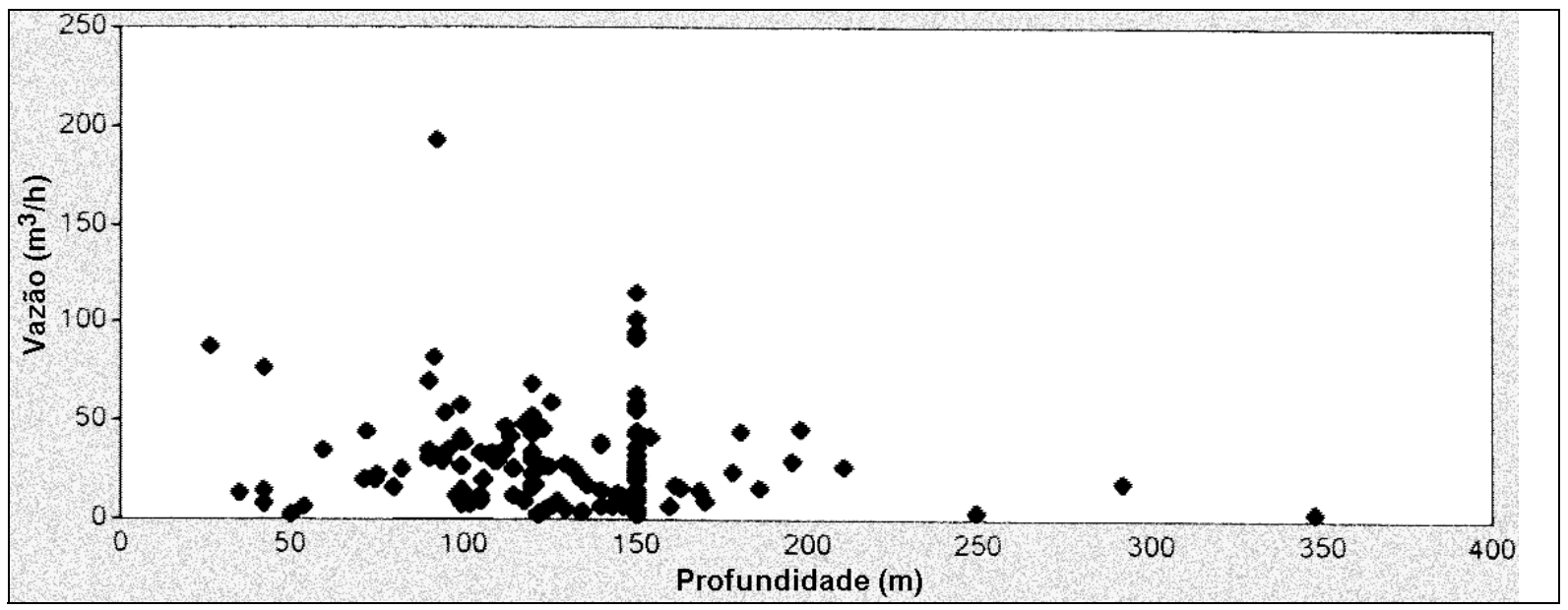

Figura 8- Relação vazão x profundidade dos poços (TAHAL/SANESUL, 1998)

Figure 8-Relation between flow and depth of the wells (TAHAL/SANESUL, 1998)

Tabela 1- Parâmetros Estatísticos para os poços de Campo Grande

Table 1-Statistical Parameters for the wells in Campo Grande

\begin{tabular}{l|r|r|r|c|c}
\hline \multicolumn{1}{c|}{ Parâmetro } & $\begin{array}{c}\text { Nível Estático } \\
(\mathbf{m})\end{array}$ & $\begin{array}{c}\text { Vazão } \\
\left(\mathbf{m}^{3} \mathbf{h}\right)\end{array}$ & $\begin{array}{c}\text { Nível } \\
\text { Dinâmico } \\
(\mathbf{m})\end{array}$ & $\begin{array}{c}\text { Rebaixamento } \\
(\mathbf{m})\end{array}$ & $\begin{array}{c}\text { Capacidade } \\
\text { Específica } \\
\mathbf{Q} / \mathbf{s}\left(\mathbf{m}^{3} / \mathbf{h} . \mathbf{m}\right)\end{array}$ \\
\hline Média & 21,38 & 21,88 & 47,39 & 26,52 & 2,07 \\
\hline Desvio Padrão & 25,98 & 19,94 & 29,76 & 21,25 & 4,47 \\
\hline Variância & 675,07 & 397,43 & 885,59 & 451,59 & 19,94 \\
\hline Mediana & 12,25 & 15,30 & 40,50 & 20,80 & 0,93 \\
\hline Coeficiente de Curtose & 8,35 & 7,41 & 2,93 & 1,83 & 63,95 \\
\hline Valor Máximo & 171,00 & 144,00 & 179,00 & 125,00 & 50,00 \\
\hline Valor Mínimo & 0,00 & 0,30 & 4,50 & 0,50 & 0,03 \\
\hline Amplitude & 171,00 & 143,70 & 174,50 & 124,50 & 49,97 pro \\
\hline
\end{tabular}


A partir de dados georreferenciados dos poços tubulares perfurados na zona de afloramento da Formação Serra Geral em território sulmatogrossense, foi elaborado o mapa potenciométrico para o aqüífero na área estudada, apresentado na figura 9 .

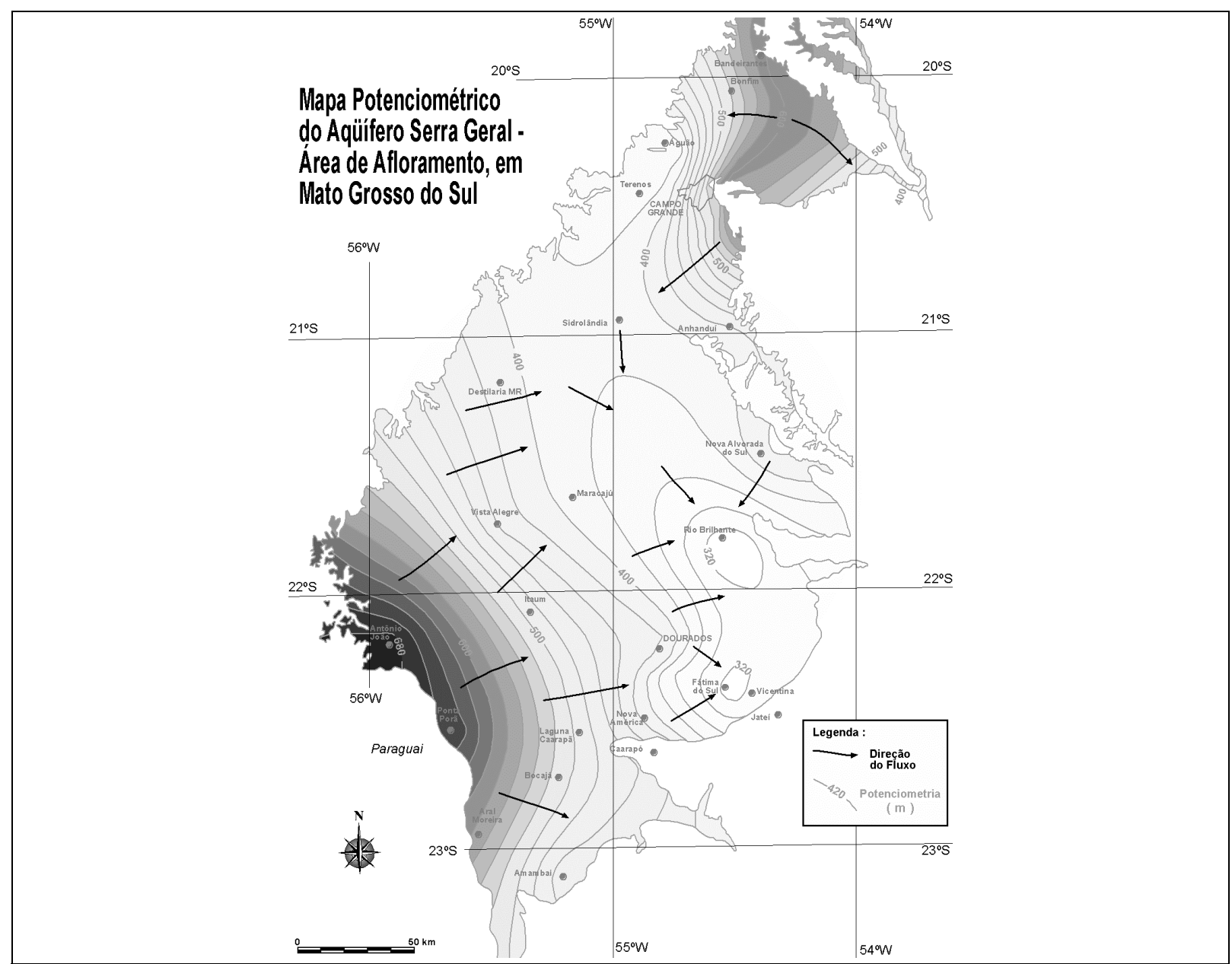

Figura 9- Direções de fluxo das águas subterrâneas no Sistema Aqüífero Serra Geral Figure 9- Groundwater flow directions in the Serra Geral Aquifer System

O mapa mostra que as linhas de fluxo convergem para uma região de "depressão" em torno de Dourados-Rio Brilhante, indicando ser uma zona de alta potencialidade para captação de água subterrânea neste aquífero. Os fluxos orientam-se nas duas extremidades da área estudada, ou seja, região sudoeste (Ponta PorãAntônio João) e região nordeste (Campo

\section{Aspectos Hidroquímicos do Sistema Aquífero Serra Geral em Mato Grosso do Sul}

Dos poços tubulares cadastrados, perfurados no Sistema Aqüífero Serra Geral, foram selecionados 79 poços para a coleta de amostras de água, além de surgências em fraturas dos basaltos, com a finalidade de se obter um quadro hidroquímico do aquífero na área de estudo.

As amostras foram coletadas em três campanhas de amostragem, realizadas no mês de outubro de 1999, a segunda em abril de 2000 e a terceira em outubro de 2000, determinando-se
Grande). A oeste de Campo Grande, o fluxo se dá na direção da bacia hidrográfica do Rio Paraguai, seguindo, ao sul desta cidade, em direção à região central da área, indicando algum controle estrutural. Tudo indica que o graben de Rio Brilhante (HARALYI, 1981), esteja concentrando o fluxo regional no Sistema Aquífero Serra Geral na área de estudo. diretamente no campo os seguintes parâmetros: temperatura, $\mathrm{pH}$, condutividade e alcalinidade.

As análises químicas foram efetuadas no Laboratório de Hidroquímica do Departamento de Geologia Aplicada - DGA, do Instituto de Geociências e Ciências Exatas - IGCE UNESP - Câmpus de Rio Claro, sendo os cátions determinados pelo método da absorção atômica e por ICP, e os ânions determinados por métodos titulométricos e colorimétricos.

As amostras coletadas apresentaram temperaturas variando entre 24 e $28^{\circ} \mathrm{C}$, e o pH entre 5,5 e 7,8 para as águas do Sistema Aqüífero Serra Geral no Estado de Mato Grosso do Sul. 
As águas contidas nos basaltos da Formação Serra Geral, de forma geral, apresentam baixa mineralização, evidenciado pelos valores de condutividade elétrica observados, entre 40 $\mu \mathrm{S} / \mathrm{cm}$ até $300 \mu \mathrm{S} / \mathrm{cm}$, notando-se uma tendência de aumento dos valores, do norte da área em direção a região de Campo Grande e, na porção sul a partir de Amambaí em direção a Aral Moreira e Ponta Porã. Na região de Dourados nota-se o aumento na direção Caarapó/Dourados - Rio Brilhante e na parte central, um aumento na condutividade na direção Maracajú - Dourados Fátima do Sul e Maracajú - Rio Brilhante. Esta configuração pode ser observada no mapa da Figura 10, sendo o aumento da condutividade, e conseqüentemente da mineralização das águas, concordante com o sentido do fluxo das águas subterrâneas no Sistema Aqüífero Serra Geral.

As águas do Aqüífero Serra Geral, segundo Lastoria (2002) são geralmente do tipo bicarbonatadas calco-magnesianas, com termos sódicos relacionados aos poços perfurados no Sistema Aqüífero Guarani, ou que podem sofrer alguma influência de misturas de águas, como o caso do poço de Fátima do Sul.

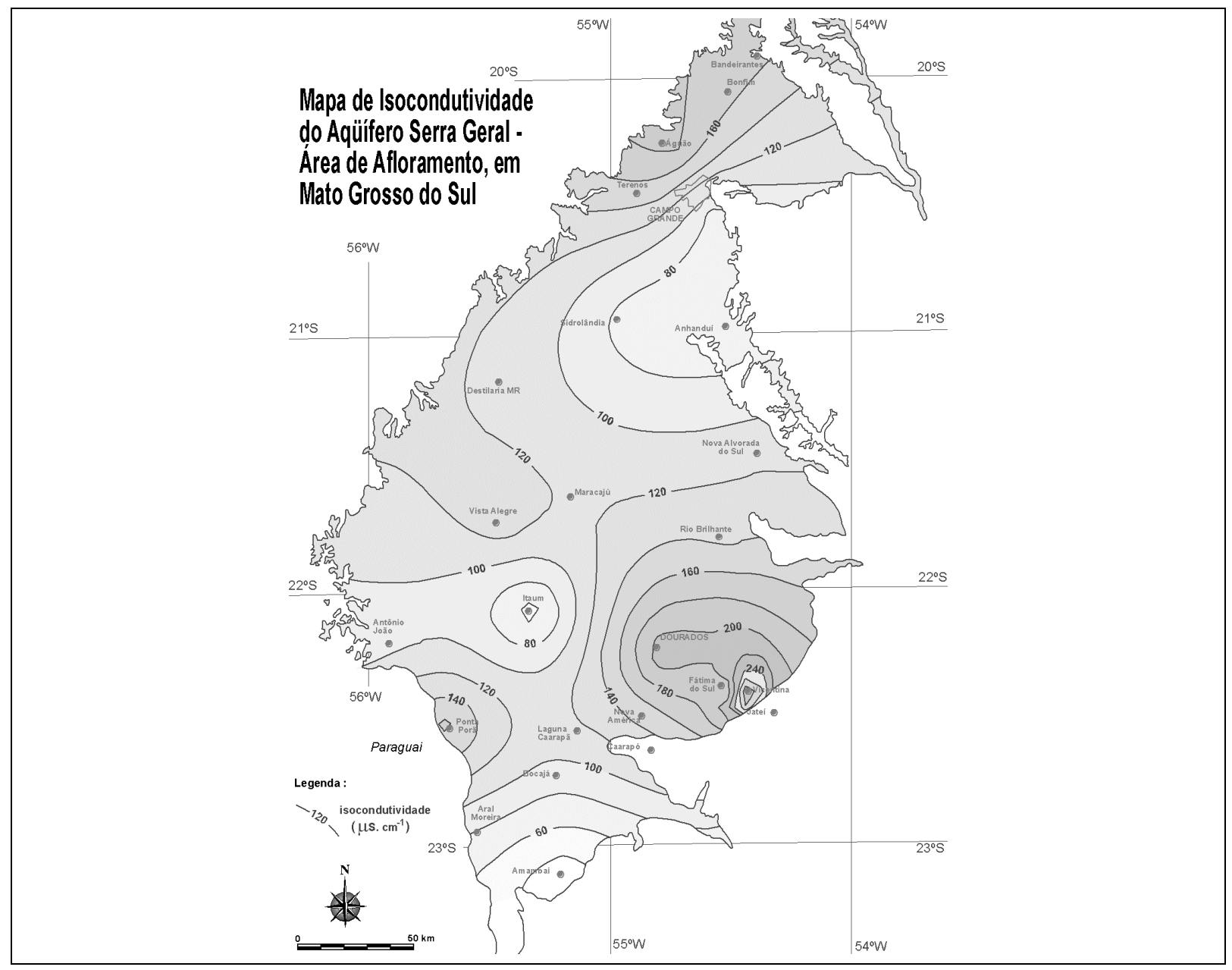

Figura 10- Mapa de Iso-condutividade das águas subterrâneas do Sistema Aqüífero Serra Geral Figure 10- Groundwater isoconductivity map from the Serra Geral Aquifer System

\section{Modelo Hidrogeológico Conceitual}

O Sistema Aqüífero Serra Geral na área de afloramentos dos derrames basálticos no Estado de Mato Grosso do Sul, pode ser caracterizado como um aqüífero regional livre, de meio fissurado, anisotrópico, que apresenta um controle estrutural marcante.

Apesar da baixa condutividade hidráulica vertical (TAHAL/SANESUL, 1998) os resultados das análises químicas, as observações de campo, a potenciometria e os dados hidrométricos dos principais rios que drenam a área de estudo, indicam a conexão vertical e de fluxo subterrâneo entre o Sistema Aquíffero Serra Geral e os Aqüíferos sotoposto (Bauru) e sobreposto (Guarani).

As relações $\mathrm{Cl} / \mathrm{HCO}_{3}$ e $\mathrm{Na} / \mathrm{Ca}+\mathrm{Mg}$, também indicam interferências entre esses aqüíferos, com valores semelhantes para todos os aqüíferos. A diferenciação só pode ser feita quando se observa 
a relação $\mathrm{Na} / \mathrm{K}$, que apresenta valores diferenciados para os basaltos (2 a 10), Bauru $(0,4$ a 4$)$ e no Sistema Aqüífero Guarani, maior que 50 (TAHAL/SANESUL, 1998).

A piezometria é um forte indicador da existência de fluxo entre os três sistemas aqüíferos. Na região de Campo Grande e Ponta Porã, os níveis piezométricos do Sistema Aquíffero Serra Geral são mais altos que os níveis piezométricos do Sistema Aqüífero Guarani, sugerindo a existência de fluxo de água descendente, enquanto que na parte central da área estudada (região de Rio Brilhante, Maracajú e Itaporã) os níveis piezométricos do Sistema Aquífero Guarani são mais elevados que os do Serra Geral, sugerindo fluxo ascendente em direção aos basaltos.

Para o estabelecimento de um modelo hidrogeológico clássico para a área em questão aproximações com relação às características do Sistema Aqüífero Serra Geral devem ser observadas, uma vez que suas propriedades indicam alto grau anisotrópico, evidenciado pela variação das capacidades específicas observadas, além do acúmulo de água apenas nas zonas fissuradas.

Regionalmente o Sistema Aqüífero Serra Geral, na área estudada, tem um controle tectônoestutural, marcado pelo alinhamento de Guapiara de direção NW, que representa o limite norte da área de afloramento, e a Serra de Maracajú, limite oeste da área de afloramento.

Os mapas potenciométrico e de isocondutividade (Figuras 13 e 14) apontam para o fluxo das águas subterrâneas no Sistema Aquíffero Serra Geral, partindo de duas regiões principais, localizadas respectivamente a nortenordeste da área (próximo a Campo Grande) e na porção sudoeste (Ponta Porã-Antônio João, na divisa com a República do Paraguai), encaminhando-se para a porção central da área e, a partir deste ponto, orientando-se em direção sudeste.

A região central da área estudada, que abrange as cidades de Maracajú, Rio Brilhante,
Dourados, Fátima do Sul e Vicentina, comportase como "zona de descarga". Muito provavelmente o sentido dos fluxos em direção a esta região central é controlado pelo Graben de Rio Brilhante (HARALYI, 1984), e o escoamento regional dos fluxos, em direção ao rio Paraná, no sentido sudeste, pode estar ocorrendo ao longo do Alinhamento do Rio Alonzo.

A percepção da ausência de controle por parte das estruturas verticais no fluxo das águas subterrâneas no Sistema Aqüífero Serra Geral, foi observada por LASTORIA (2002) e LASTORIA et al. (2005), relacionando as capacidades específicas dos poços e a densidade de lineamentos verticais em diversas regiões de Mato Grosso do Sul, constatando-se que não existe uma relação direta entre os poços de maior capacidade produtiva e suas locações sobre os lineamentos mapeados.

Diversos fatores apontam para a indicação do fluxo horizontal, como a principal zona de circulação e acúmulo de água subterrânea no Aqüífero Serra Geral na área de estudo, podendose destacar dentre eles, a presença comum de "cachoeiras" em alguns poços perfurados nos basaltos, formadas pela ocorrência de zonas menos produtivas em um horizonte superior, que não consegue equilibrar a pressão hidrostática do nível inferior.

As constatações mais marcantes do domínio da circulação de água em fraturas sub-horizontais na área de afloramento dos basaltos em Mato Grosso do Sul, podem ser observadas em frentes de lavra de pedreiras que exploram o basalto para a obtenção de brita.

Em pedreiras onde existe a presença intensa de níveis de fraturamento horizontal, verifica-se a ocorrência de água. Por outro lado, nos locais onde este fraturamento não foi observado, ou não foi atingido, predominando diáclases verticais, ou fraturas horizontais de pequeno porte, não são observados indícios de circulação de água (Fotos 1 e 2).

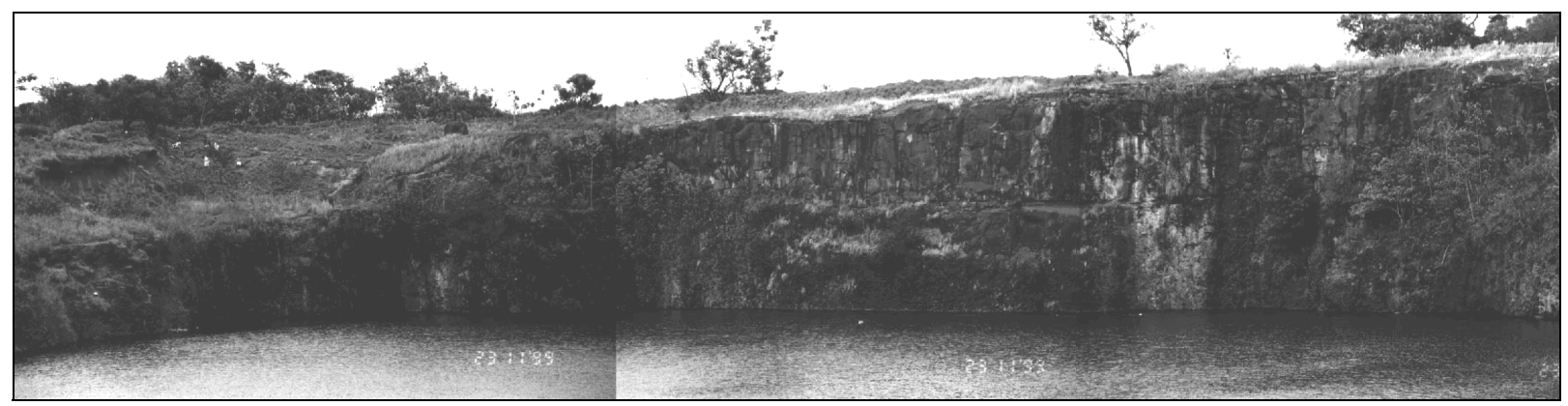

Foto 1- Fonte de água no diaclasamento horizontal dos basaltos da Pedreira SULTEPA (Dourados)

Photo 1- Water spring in basalt horizontal joint - SULTEPA Quarry (Dourados) 


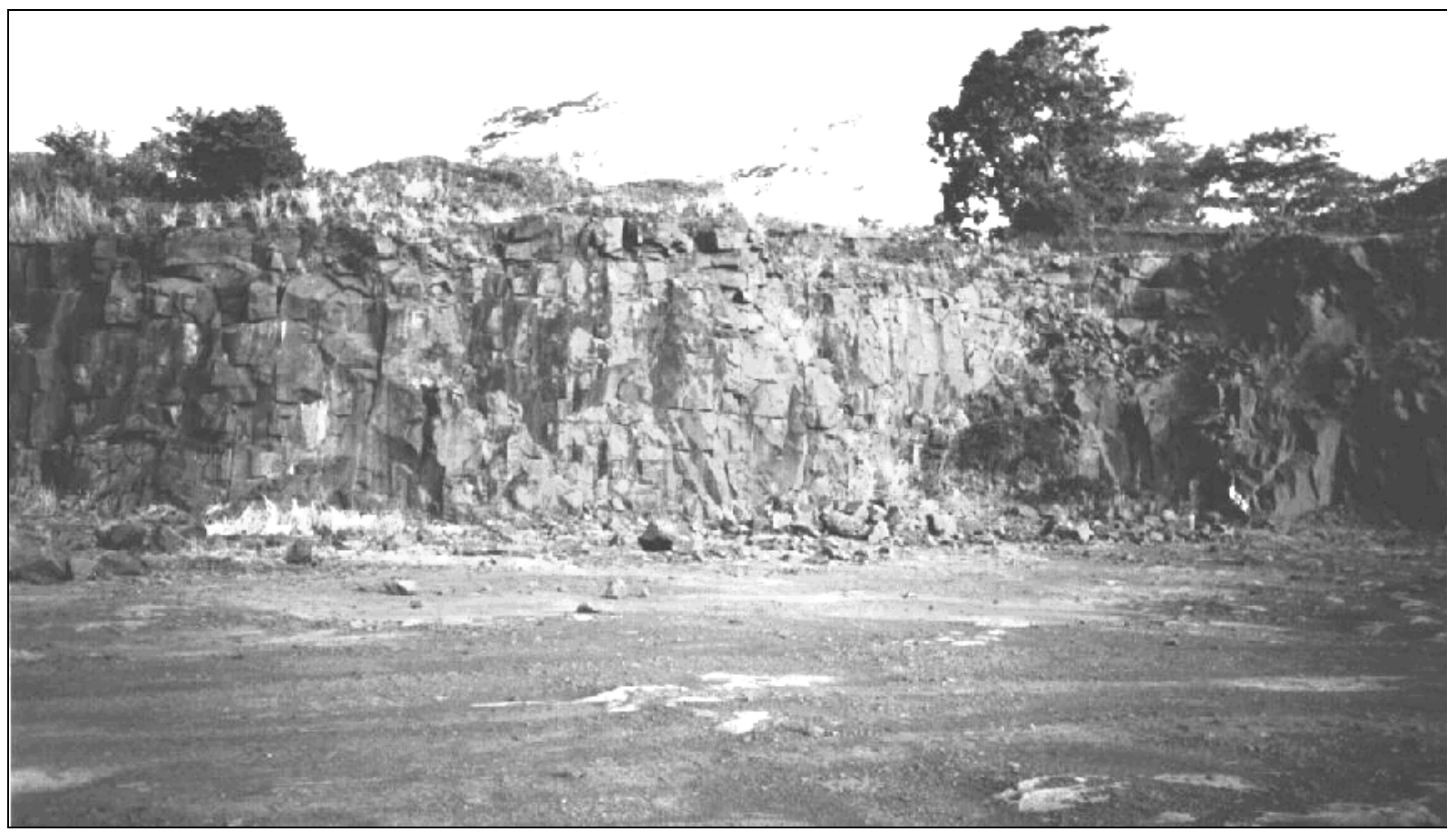

Foto 2- Pedreira da NOSDE - Dourados, observando-se intenso diaclasamento vertical sem acúmulo de água Photo 2- NOSDE Quarry - Dourados, showing a very strong vertical fracture system, without water

\section{Conclusões}

$\mathrm{Na}$ área de estudo, o Sistema Aqüífero Serra Geral apresenta um fluxo anisotrópico, em função da heterogeneidade de sua permoporosidade, com fissuras horizontais e verticais.

A movimentação da água subterrânea nesta formação se dá na forma de um aquífero livre, guardando uma associação direta com a drenagem superficial e garantindo a manutenção de seu nível de base. Potencialmente a sua recarga ocorre em toda a área de afloramento dos derrames basálticos. No entanto, as estruturas regionais que afetam as rochas desta unidade hidroestratigráfica provavelmente controlam o fluxo subterrâneo regional.

A análise do mapa potenciométrico (Figura 9) indica que a região de Campo Grande, ao norte, e a região de Ponta Porã - Antônio João, no sudoeste, atuam como zonas onde ocorre a maior contribuição hídrica para o aqüífero. Os fluxos provenientes destas duas regiões encaminham-se para a área de Maracajú - Rio Brilhante - Dourados, drenando em sentido sudeste a partir de Fátima do Sul - Vicentina, para o rio Paraná.
A condutividade elétrica das águas subterrâneas, que reflete a mineralização da água no decorrer do seu fluxo, indica exatamente o modelo de movimentação da água subterrânea, apontado pela potenciometria.

$\mathrm{Na}$ região central da área estudada, o nível piezométrico do Sistema Aqüífero Guarani, é superior ao nível piezométrico do Sistema Aqüífero Serra Geral, propiciando um fluxo ascendente, ou seja, fortalecendo a hipótese de que possa ocorrer, localmente uma alimentação dos basaltos pelo aquífero sotoposto.

A proposição de um modelo hidrogeológico conceitual para o Sistema Aqüífero Serra Geral na área, baseou-se na análise dos fluxos de água em estruturas verticais e horizontais, presentes nos derrames basálticos, e com base nas evidências observadas, foi possível associar às juntas e ao sistema de diaclasamento horizontal, localizado no topo e na base dos derrames, bem como no contato entre derrames, o principal condicionante do fluxo e armazenamento das águas subterrâneas, notadamente através de juntas horizontais de grande continuidade (Foto 1). 


\section{REFERÊNCIAS}

ALMEIDA, F.F.M. Origem e evolução da plataforma continental brasileira. Boletim da Divisão de Geologia e Mineralogia, Departamento Nacional da Produção Mineral. n. 241, Rio de Janeiro, 36p., 1967.

BAGOLINI, B. Osservazioni geologiche e geomorfologiche sugli espandimenti basaltici del Bacino dell'Alto Paraná nel Brasile Meridionale. Museo Tridentino de Science Naturali. Trento, Itália, p. 69-119, 1971.

CORDANI, U.G; VANDOROS, P. Basaltics rocks of the Paraná Basin: Problems in Brazilian gondwana geology. Plate LXXVIII, CNPq, Boletim Paranaense de Geografia. Curitiba, v.21(22): 207-231, 1967.

FULFARO, V.J.; PERINOTTO, J.A.J. Geomorfologia do Estado de Mato Grosso do Sul e o arcabouço estrutural. In: $38^{\circ}$ CONGRESSO BRASILEIRO DE GEOLOGIA, 1994, Camburiú, SBG...Boletim de Resumos Expandidos, v.3, p. 197-198, 1994.

HARALY, N.D.E. O significado tectônico das anomalias de gravidade na Bacia do Paraná. In: $3^{\circ}$ SIMPÓSIO REGIONAL DE GEOLOGIA, 1981, Curitiba, SBG... Anais, v.1, p. 274-281, 1981.

HASSUI, Y.; HARALY, N.L.E.; SENA COSTA, J.B. Megaestruturação Pré-Cambriana do Território Brasileiro Baseada em Dados Geofísicos e Geológicos. Geociências/UNESP. v.12(1): 07.-31, 1993.

HAUSMAN, A. Aspectos hidrogeológicos dos aqüíferos fissurados no sul da Bacia do Paraná. Revista Água Subterrânea. São Paulo, v.1(4): 44-60, 1974.

LASTORIA, G. Hidrogeologia da Formação Serra Geral no Estado de Mato Grosso do Sul. Rio Claro, 2002. 133 p. Tese (Doutoramento em Geociências e Meio Ambiente). Instituto de Geociências e Ciências Exatas - IGCE - UNESP - Rio Claro, 2002.
LASTORIA, G.; SINELLI, O.; CHANG, H.K.; PARANHOS FILHO, A.C.; FIORI, A.P. Relação entre a Produção de Poços Tubulares e os Lineamentos nos Basaltos da Formação Serra Geral em Mato Grosso do Sul. In: X SIMPÓSIO NACIONAL DE ESTUDOS TECTÔNICOS, 2005. Curitiba, SBG... Boletim de Resumos Expandidos. p.258-260, 2005.

NORTHFLEET, A.A.; MEDEIROS, R.A.; MUHLMANN, H. Reavaliação dos dados geológicos da Bacia do Paraná. Boletim Técnico da Petrobrás, Rio de Janeiro. v. 12(3): 291-346, 1969.

PIPER, A.M. A graphic procedure in the geochemical interpretation of water analyses. American Geophysical Union Transactions v.25, p. 914-923, 1944.

REBOUÇAS, A.C.; FRAGA, C.G. Hidrogeologia das rochas vulcânicas do Brasil. Revista Brasileira de Águas Subterrâneas. São Paulo, n.12, p.29-55, 1988. SEFOP-MS. Anuário Estatístico de Mato Grosso do Sul - Ano 1988. Secretária de Finanças, Orçamento e Planejamento. Campo Grande, 415p., 1988.

TAHAL / SANESUL. Estudos Hidrogeológicos de Mato Grosso do Sul. Relatório Final. Campo Grande, mapas, v.I, II, 736p., 1998.

ZALÁN, P.V.; WOLFF, S.; CONCEIÇÃO, J.C.J.; MARQUES, A.; ASTOLFI, M.A.M.; VIEIRA, I.S.; APPI, V.T.; ZANOTTO, O.A. Bacia do Paraná. In: RAJA GABAGLIA, G.P.; MILANI, E.J. (Coord). Origem e evolução de Bacias Sedimentares. Petrobrás Rio de Janeiro. p. 135-167, 1990.

\section{AGRADECIMENTOS}

Os autores expressam agradecimentos à FAPESP (Processo 99/2451-0), pelo suporte financeiro a este trabalho. 